Egyptian

Orthodontic Journal

\title{
TONGUE VOLUME IN RELATION TO DENTAL ARCH CONFIGURATION IN MOUTH BREATHERS
}

\author{
El.Mehy Gh.A* and El.Bialy A.A.**
}

ABSTRACT

This study was designed to measure the tongue volume by a simplified method, and to evaluate the effects of tongue volume on both maxillary and mandibular dental arch lengths and widths. Forty children with a mean ages12 years old were selected for this study. The mouth breather group were consisted of 20 mouth breathing children, and the other 20 for the nasal breathing as a control group . The mouth breathers have an important character that the tongue is always restricted to the lower dental arch leaving the upper dental arch intact. So a comparative study was done to evaluate the effects of tongue volume on both arches in nasal breathing group (normal contro( group) and in mouth breathing group. It was found that the mean tongue volume in the mouth breathing group was 510.6. with S.D +9.6 while for nasal breathing group was 523.4 with S.D + 10.3. Moderate to low or even negative correlations were found between the mouth breather tongue volumes and dental arch measurements especially in posterior region. Surprisingly there were no correlations recorded between tongue volume and dental arch measurements in nasal breathing group. So on the bases of the results obtained from this study it was found that there was variations of the effect of tongue volume on dental arch configuration in mouth breathing group if compared to the nasal breather group. Tongue impression method for dental casts could be considered as a reliable method for recording tongue volume.

* Ghada A.El.Mehy, Lecturer of Orthodontics Fac. of Dent. Tanta University.

${ }^{* *}$ Ahmad A.El.Bialy, Asso.Prof. and acting head of Orth. Dep. Almansoura University. 
Egyptian

Orthodontic Journal

\section{INTRODUCTION}

Since precise measurements of tongue volume has been assumed to be difficult, very little information is available on the relation between the tongue and oral cavity ${ }^{(23)}$. Form and function of the oral soft tissues, and the tongue in particular have been related to the growth of the oral cavity ${ }^{(16)}$, the size of the oral cavity ${ }^{(15)}$, the development of malocclusion, and speech defects ${ }^{(9)}$. Tongue function has been studied to observe the direction and amount of movement (2) and the pressure exerted ${ }^{(7,18)}$. The form of the tongue has been studied radiographically using cephalometric techniques ${ }^{(4,6,5,13)}$ using computerized tomography ${ }^{(20)}$ and by MRI ${ }^{(22)}$ and the form in relation to malocclusions ${ }^{(1)}$. The importance of the tongue to the form of the jaws and dental arches has long been accepted. Clear-cut differences in arch width and arch height are observed between mouth and nasal breathing. Course measurements, e.g. duration of tongue contact with the gum, are not feasible with traditional measuring methods ${ }^{(21)}$.

Since the tongue is located inside the dental arch and almost always in contact with the teeth, unusual tongue volume or abnormal tongue movement may deform dentition, especially when they are growing ${ }^{(24)}$.

Leech $(1958)^{(14)}$ found that mouth breathing does not seem to affect the skeletal or occlusal pattern. Others ${ }^{(10)}$ observed that mouth breathing does not produce deformities of the jaws and malocclusions nor does it result in the development of adenoidal faces. O'Ryan et al $(1982)^{(19)}$ in a critical review of the literature did not support the assumption that mouth breathing that result from a compromised nasal airway is of major etiologic significance in the development of the long face syndrome.

Because upper airway obstruction was an obstacle to normal dentofacial development, mouth breathing children deserved prompt attention before growth has proceeded irreversible ${ }^{(8)}$.

Several attempts were made to measure tongue volume clinically and radio- graphically and its relation to dental arch configuration mainly the lower dental arch. The most of these trials unfortunately were depended on the patient co-operation. The method described in this work could be more helpful in understanding the role of tongue volume in upper and lower dental arch configurations.

On other hand mouth breathing might lead to postural changes such as lowered position of the mandible, raised position of the head, low posture of the 
hyoid bone and anterior inferior position of the tongue According to this conflict more attention must be made to understand all about the relation between mouth breathing and oral structures.

\section{Aim of the work}

The aims of this study were:-

1- To introduce a simplified method to measure the tongue volume.

2- To evaluate its effects on upper and lower dental arch configurations in mouth breathers compared to normal nasal breathers (control group).

\section{Materials and methods}

The data consisted of 40 patients whom attended at Orthodontic Department, Faculty of Dentistry, Tanta University.

Their mean ages were 12 years old. Twenty of the cases were mouth breathers and the other twenty were normal nasal breathers (control group), All were represented Class I Angle of malocclusion.

Upper and lower alginate impressions were taken for dental arches in mouth and nasal breathers groups, no muscle trimming was done. Their models were prepared as described by Allen J. Moses (1991). to be suitable for taking the alginate impressions for tongue volume (Fig. 1, and 2).

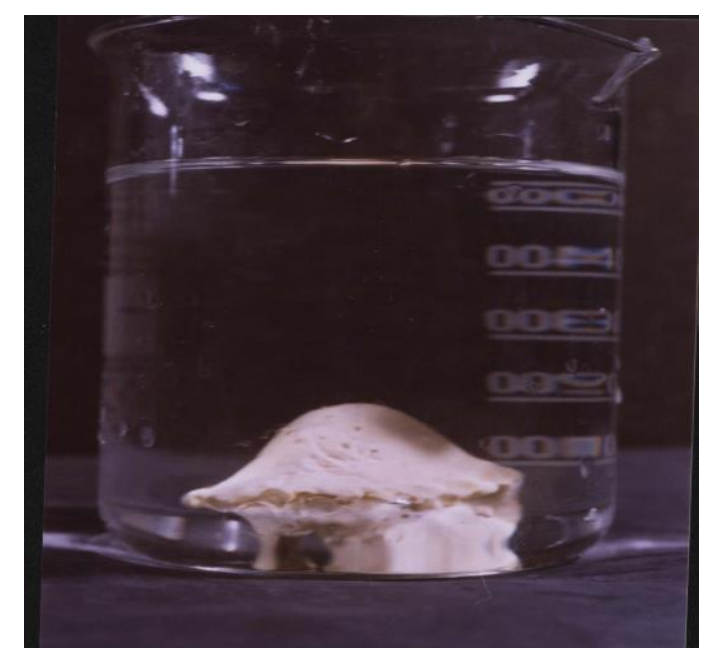

Fig (1). The impression in the graduated beaker 


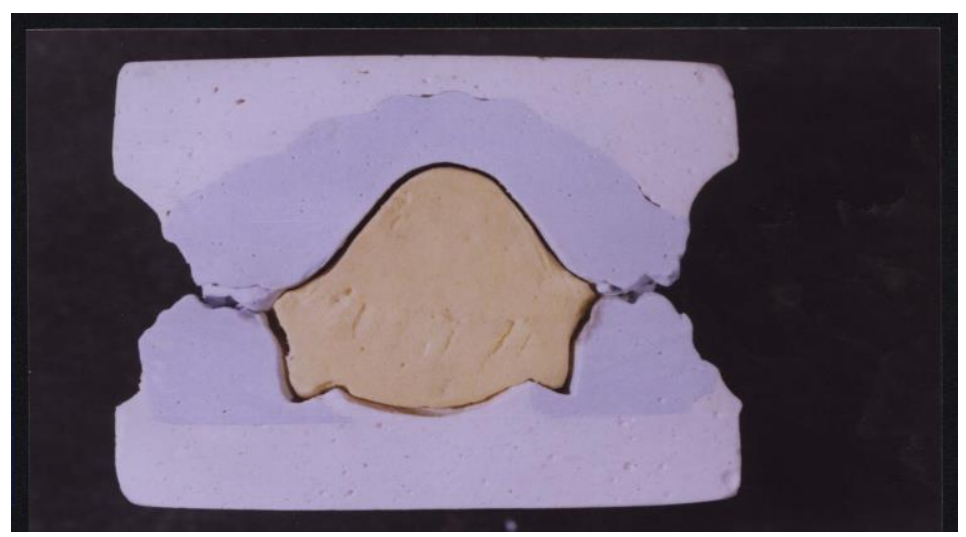

Fig.(2): The models cut from behind, the impression material, fill the tongue space.

\section{Volumetric analysis.}

Stone models were constructed. The models were luted together with sticky wax in centric occlusion and alginate was vibrated into the tongue space between the arches. When the impression material set, the models were separated and the alginate mould was placed in a 600-milliter beaker calibrated in 10milliter increments. The volume of water displaced by the alginate was measured and defined as " tongue volume in centric occlusion".

All measurements were recorded to the nearst $1.0 \mathrm{~mm}$. for dental cast, and $1.0 \mathrm{~cm}^{3}$ for tongue volume measurements.

\section{Dental arch measurements.}

Three dental measurements were taken for both arches.

1- Inter-molar width (between mesio-buccal cusp tips of upper or lower first permanent molars).

2- Inter-canine width (between cusp tips of upper and lower permanent canines).

3- Upper and lower arch lengths were measured along a line drown perpendicular from the midline between the central incisors on inter molar line (drown from the mesio-buccal cusp tips of the upper or lower first permanent molars).

All the measurements were repeated to check any error of the methods. 
Egyptian

Orthodontic Journal

\section{RESULTS}

Using SPSS 8.0 programmer for windows to analyze the data collected for this study.

Table 1: Total tongue volume of mouth and nasal (normal control group) breather children expressed in milliliters.

\begin{tabular}{|l|c|c|c|c|}
\hline \multicolumn{1}{|c|}{ Variables } & Mean & Std error of mean & S.D & T test \\
\hline Mouth breathers & $510.6 \mathrm{ml}$. & 1.1274 & \pm 3.5 & \multirow{2}{*}{$0.003^{*}$} \\
\cline { 1 - 4 } Nasal breathers & $523.1 \mathrm{ml}$. & 0.8360 & \pm 2.6 & \\
\hline
\end{tabular}

$\mathbf{n}=20 \quad \mathrm{~N}=40$

* significant at $5 \%$ level.

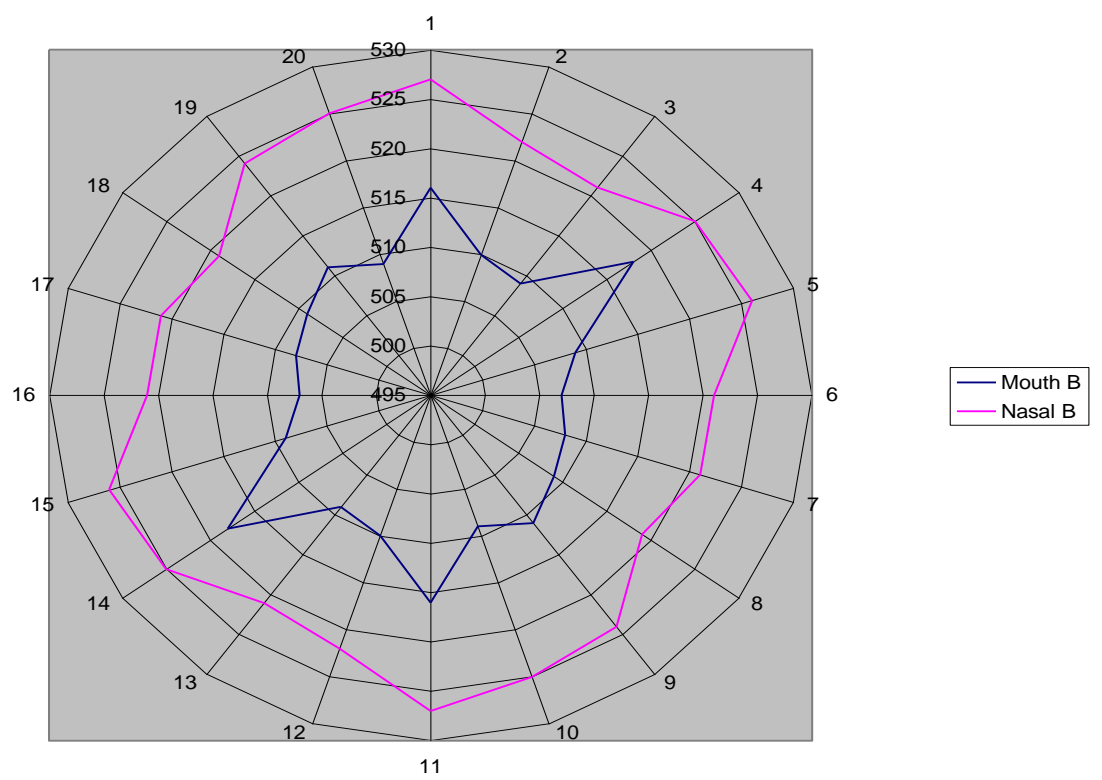

Graph 1: total tongue volume of mouth and nasal breather groups

Mouth breathers

Nasal breathers 
It was found that the mean value of tongue volume recorded for mouth breather group was $510.6 \mathrm{ml}$. with S.D \pm 3 , while it was $523.1 \mathrm{ml}$ with \pm 2.6 for nasal breathing group. There was a significant difference between the two means (Table 1 and Graph 1.).

Arch length analysis were summarized in Table 2 and Graph 2. for the upper dental casts, and Table 3 and Graph 3 for the lower dental casts in cases of mouth and nasal breathing groups

Table 2: Upper dental arch analysis for mouth and nasal breather groups.

\begin{tabular}{|l|c|c|c|}
\hline Variables & Nasal breathers & Mouth breathers & t- test \\
\hline $\begin{array}{l}\text { Upper inter } \\
\text { molar width }\end{array}$ & $\begin{array}{c}\mathrm{X}=49 \mathrm{~mm} . \\
\text { U 6-6 }\end{array}$ & $\begin{array}{c}\mathrm{X}=42.3 \mathrm{~mm} . \\
\mathrm{S} . \mathrm{D} \pm 3.4\end{array}$ & $0.001^{*}$ \\
\hline $\begin{array}{l}\text { Upper inter } \\
\text { canine width. } \\
\text { U 3-3 }\end{array}$ & $\begin{array}{c}\mathrm{X}=35.26 \mathrm{~mm} . \\
\mathrm{S} . \mathrm{D} \pm 3.6\end{array}$ & $\begin{array}{c}\mathrm{X}=29.94 \\
\mathrm{~S} . \mathrm{D} \pm 2.5\end{array}$ & $0.004^{*}$ \\
\hline $\begin{array}{l}\text { Upper arch } \\
\text { length UAL }\end{array}$ & $\mathrm{X}=31.13 \mathrm{~mm}$. & $\mathrm{X}=30.15 \mathrm{~mm}$. & $0.237 \mathrm{~ns}$. \\
\hline
\end{tabular}

$\mathbf{n}=20$

* Significant at 0.05 level.

ns $=$ no significant

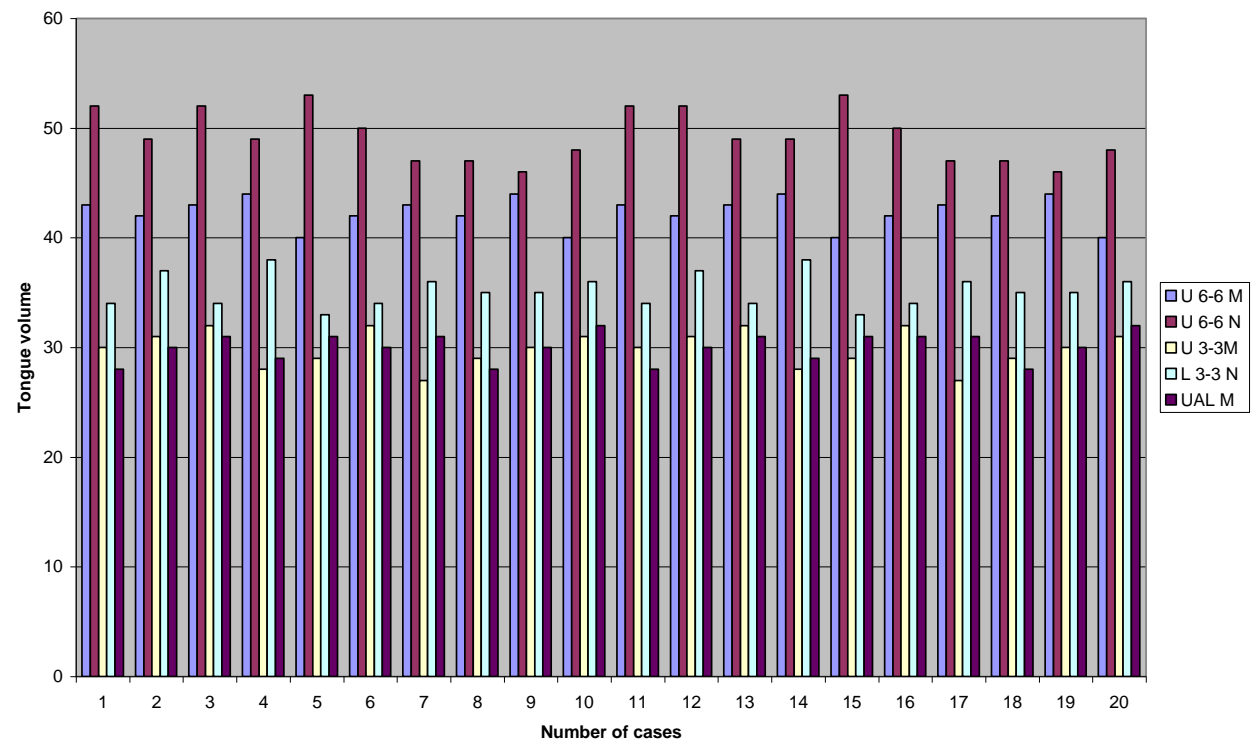

Fig.2: Comparisons between upper dental arch measurements in mouth and nasal breathing groups. 
Egyptian

Orthodontic Journal

Table (3): Lower dental arch length analysis for mouth and nasal breather groups.

\begin{tabular}{|l|c|c|c|}
\hline \multicolumn{1}{|c|}{ Variables } & Nasal breathers & Mouth breathers & t- test \\
\hline $\begin{array}{l}\text { Lower inter } \\
\text { molar width } \\
\text { L 6-6 }\end{array}$ & $\mathrm{X}=42.6 \mathrm{~mm}$ \\
$\mathrm{~S} . \mathrm{D} \pm 2.4$ & $\mathrm{X}=39.6$ & $0.006^{*}$ \\
\hline $\begin{array}{l}\text { Lower inter } \\
\text { canine width }\end{array}$ & $\mathrm{X}=28.5 \mathrm{~mm} \pm 3.2$ & $\mathrm{X}=25.3 \mathrm{~mm}$ & $0.041^{*}$ \\
L 3-3 & $\mathrm{S} . \mathrm{D} \pm 4.2$ & $\mathrm{~S} . \mathrm{D} \pm 2.6$ & \\
\hline $\begin{array}{l}\text { Lower arch } \\
\text { length LAL }\end{array}$ & $\mathrm{X}=21.8 \mathrm{~mm}$ & $\mathrm{X}=21.6$ & $0.312 \mathrm{~ns}$ \\
\hline
\end{tabular}

$\mathbf{n}=20$

*Significant at 5\% level.

$\mathrm{ns}=$ nonsignificant.

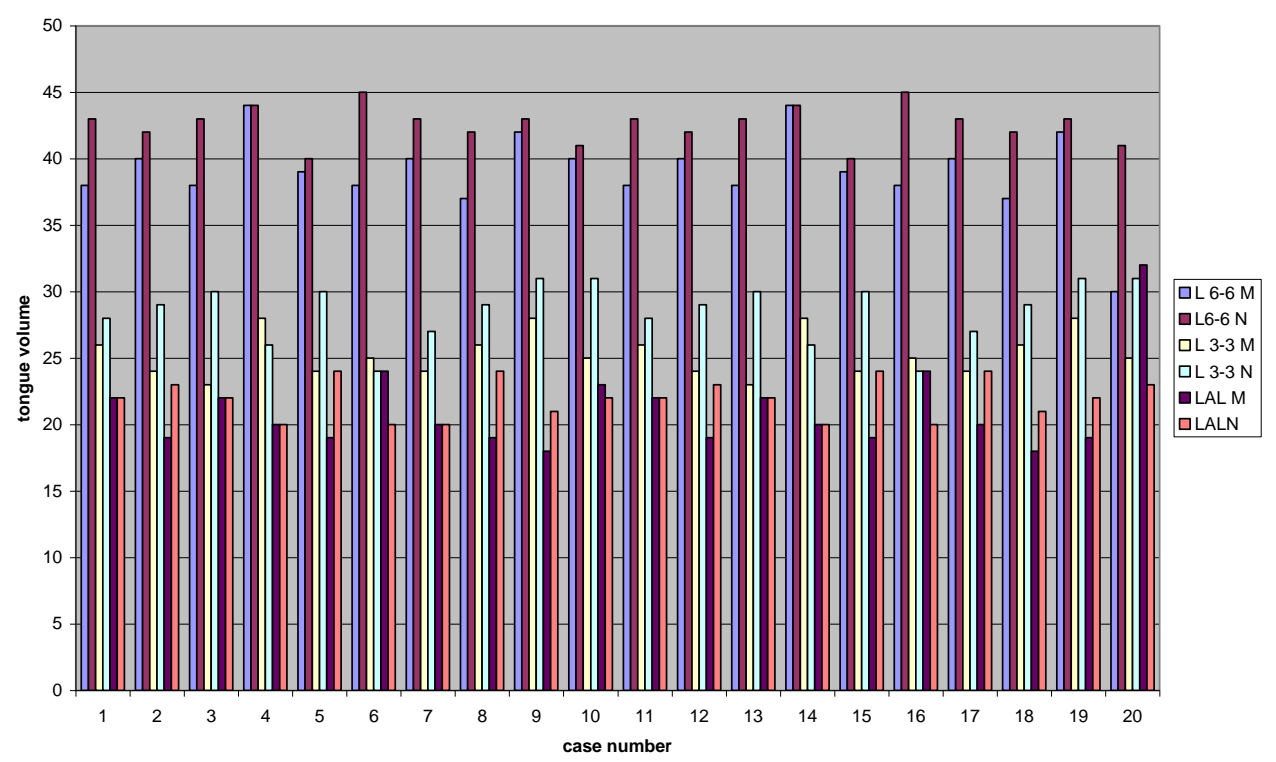

Fig.(3): Comparisons between lower arch measurements of mouth and nasal breathing groups. 
Correlation coefficients between tongue volumes and dental arch length readings were demonstrated in Table 4 . It is generally accepted that the values above 0.7 had strong or high correlation and below 0.4 have little clinical significance. So there were a moderate to low correlation between the tongue volume versus upper 6-6 (0.510), L 6-6 (0.535), and L 3-3 (0.644) in mouth breathers group.

Surprisingly, there were no correlations recorded between the tongue volume and the dental arch measurements in nasal breathing group.

Table 4: Correlation coefficients volumes measured by water displacement for dental cast measurements in mouth and nasal breathers.

\begin{tabular}{|l|c|c|}
\hline \multicolumn{1}{|c|}{ Variables } & Mouth breathers & Nasal breathers \\
\hline $\begin{array}{l}\text { Upper inter molar width } \\
\text { (U 6-6) }\end{array}$ & 0.510 & -.127 \\
\hline $\begin{array}{l}\text { Upper inter canine width } \\
\text { (U 3-3) }\end{array}$ & -0.307 & -0.077 \\
\hline Upper arch lengthU.A.L. & -0.561 & 0.032 \\
\hline $\begin{array}{l}\text { Lower inter molar width } \\
\text { (L 6-6) }\end{array}$ & 0.535 & 0.385 \\
\hline $\begin{array}{l}\text { Lower inter canine width } \\
\text { L 3-3) }\end{array}$ & 0.644 & 0.313 \\
\hline Lower arch length (LAL) & -0.019 & 0.124 \\
\hline
\end{tabular}

\section{DISCUSSION}

Several methods were done for assessing tongue volumes were examined. Visual appraisal of tongue size was found to be insufficient, since it depended upon the examiner's subjectivity.

In cephalometric method the dimension of the tongue on the cephalogram did not necessarily reveal an accurate measure of the tongue volume. So in order to enhance the reliability of the recorded tongue volume, a three-dimensional information were taken through impressions of the tongue volume inside the dental casts in centric occlusion, which followed in this study. 
The data recorded in this work revealed that there were a conflict between the results in which there were a significant differences between the mouth breather and nasal breathing groups for all dental measurements except upper and lower dental arch lengths (Table 2, and 3).

Besides, moderate, low, and even negative correlations were found in the dental casts measurements and tongue volume in the mouth breathing group. No correlations were found between the tongue volume and dental cast measurements in nasal breathing groups.

The same results were supported with the results of Takada et al (1980) ${ }^{(\mathbf{2 3})}$ who concluded that tongue volume did not correlate with the horizontal dimensions such as the intermolar width, interbicuspid width and the arch length. However, in regard to the vertical direction, a high correlation between the tongue volume and the depth of the floor of the mouth was recognized. Again O'Ryan et al (1982) ${ }^{(\mathbf{1 9 )}}$ introduced a critical review of the literature did not support the assumption that mouth breathing that results from a compromised nasal airway was of a major etiologic significance in the development of the long- face syndrome.

Moreover, experimental studies especially the study of Harvold et al (1981), stated that" The chronic absence of active nasal respiration has any effect on the growth of the skull".

Finally, the genetic factors which basically define the morphology of the skeletal unit and the teeth and environmental factors, such as the pressure of the lip or cheek, forces from dental occlusion, and the periodontal membrane, may also play an important role in the maintenance of the forms of the dental arches and the palate Proffit (1978). On the other hand Tamari et al $(1991)^{(24)}$ in their work on Japanese population they found that there were strong correlation between the tongue volume and lower dental arch. Esmail et al $(1991)^{(11)}$, whom studied the effects of mouth breathing on the growth of dental arch in Egyptian population concluded that the heredity could play a major role in the growth of the craniofacial structures with little effects on dental arch especially the lower dental arch in mouth breathers.

\section{Conclusions}

1- The impression method for dental cast in centric occlusion followed in this study for calculation of the tongue volume is considered a more reliable way for tongue volume determination.

2- There is a conflict about the effect of mouth breathing on dental arch configuration. 
3- There are varying levels of correlation between tongue volume and oral cavity dimensions.

4- More studies must be followed to reveal the previous dilemma.

\section{REFERENCES}

1- Aboul -Azm S.F., Marzouk W., and Ebrahium A G. : Assessment of tongue position in different types of malocclusion. Egyptian Orthodontic J. Vol. 24:155-176, Dec 2003.

2- Adran, G.M. and Kemp, F.H. A radiographic study of movements of the tongue in swallowing. Dental Practitioner 1955 5:242-261.

3- Allen J. Mosses. Analysis of functional appliances Vol 84, Number 4. The official publication of the Chicago Dental Society, Web site1991.

4- Cohen, A. M. and Vig, P. S.. A serial growth study of the tongue and intermaxillary space. Angle Orthod. 1976 46:332- 337.

5- Cookson, A. M.. Tongue resting position. Transactions of the British Society for the study in Orthodontics pp 1966/67. 119-123.

6- Eifert, D. F.. A roentgenographic cephalometric study of the tongue. Am. J. Orthod. 1960 46:226-227.

7- Fairbanks, G. and Beeout, B.. A study of minor organic deviations in "functional" disorders of articulation. 3. The Tongue. /. Speech Hear. Dis 1950 $15: 348-352$.

8- Faria P T M, Ruellas A C de O, Matsumoto $m$ a n, Anselmo-Lima, W T, Pereira F C. Dentofacial morphology of mouth breathing children. Braz Dent J (2002) II vol. 13(2): 129-132.

9- Foster, T. D. A textbook of Orthodontics. Pub. Blackwell Scientific Publications Oxford 1975.

10- 10. Gwynne- Evans E, Ballard C F. Discussion on the mouth breather. Proc R Soc Me 1959; 51: 279-85.

11- Esmaiel, H, El-Hendawy F, El-Sakhawy M. Study of the effect of mode of breathing on growth of the dental arches and skeletal relationship in Egyptian families. Accepted for publication, Tanta Medical J. June 1991.

12- Harvold EP, Vargervik, Chierici G. Primate experiments on oral respiration. Am J Orthod.1981;79:359-73. 
13- Hopkin, G. B.. Tongue level in Angle's Class II and Class III malocclusions. Transactions of the European Orthodontic society pp. 1963 399-403.

14- Leech H L. A clinical analysis of the orofacial morphology and behavior of 500 patients attending an upper respiratory research clinic . Dent Practit. $1958 ; 9: 57-68$.

15- McGlone, R. E. and Proffit, W. R.. Correlation between functional lingual pressure and oral cavity size. Cleft Pal. J. 1972 9:229-235.

16- Moss, M. L.. The primary role of functional matrices in facial growth. Am. J. Orthod. 1969 55:556-557.

17- Proffit, W. R., Palmer, J. M. and Kydd, W. L. Evaluation of tongue pressures during speech. Folia Fhoniatrica 17:115-128.

18- Proffit, W.R. 1978: Equilibrium Theory Revisited: Factors Influencing Position of the Teeth, Angle Orthod. 1965. 48:175-186.

19- O'Ryan FS, Gallagher DM, LaBanc JP, Epker BN. The relation between nasorespiratory function and dentofacial morphology. A review. Am J Orthod 1982;82:403-410.

20- Roehm E.G.: Computed tomographic measurement of tongue volume relative to its surrounding space. Am. J. Orthod.1982;81:72.

21- Schuster G, Schopf PM. Valentin H. Development and testing for orthodontic functional analysis. J Orofac. Orthop. 1997; 58(5):254-610.

22- Stone M., Edward P, Davis and Andrew S. Dolas, Moriel NessAiver and Rao Gullapalli, and William S. Levine: Modeling the motion of the internal tongue form tagged cine-MRI images.

23- dentofacial orthopedics. AngleOrthod 1980; 50:147-164.

24- Takada K, Sakuda M, Yoshida K, Kawamura Y: Relation between tongue volume and capacity of the oral cavity proper: J. Den. Res.59(12):20262031, December 1980.

25- Tamari K, Shimizu K, Ichinose M, Nakata S, and Takahama Y Relationship between tongue volume and lower dental arch size, Am J Orthod Dentofac. Orthop. 1991, 100: 453-8. 